\title{
France and US in late conversion to 'zero-yield' nuclear test ban
}

Paris. Prospects for the introduction of a Comprehensive Test Ban Treaty (CTBT) were revived last week after France confirmed that it will support a ban on all nuclear tests, no matter how small, from next year (see Nature 376, 283; 1995).

The French decision - which has been interpreted as an attempt to turn the tables on critics of its planned series of tests in the South Pacific - was immediately followed by a similar endorsement of a total test ban by the US President Bill Clinton. "I applaud the French statement," he said. "It will make it much easier for us to get a comprehensive test ban."

Indeed, the French and US statements will break the deadlock in negotiations on the CTBT at the Conference on Disarmament in Geneva, where the permanent five nuclear weapons-state members of the United Nation's Security Council - France, the United States, China, Russia and the United Kingdom - have been considering introducing a loophole in the ban that would allow low yield nuclear explosions of up to 1 kiloton (see Nature 376, 283; 1995).

Although such tests would not allow full testing of conventional nuclear weapons, observers argue that they would provide nuclear states with data that would give them added confidence in a new design. Non-nuclear weapons nations oppose a treaty containing such a loophole, as they consider it would drop disarmament from the goals of the CTBT.

By ruling out large tests, the US and France will make the treaty easier to accept for non-nuclear nations that are either unable or unwilling to carry out such tests. These nations agreed to an indefinite extension of the Nuclear Non-Proliferation Treaty (NPT) earlier this year on the understanding that a test ban would be sufficiently comprehensive to encourage disarmament as well as non-proliferation.

In particular, the clarity of last week's statement by Gérard Errera, the French delegate to the Conference on Disarmament which said that France would press for a ban on "all tests of nuclear arms and all nuclear explosions" - if confirmed in a formal treaty, would dispel suspicions that France intends to develop a new generation of weapons.

"We are very happy with the statement, it's as good as we hoped but better than we expected," says Patricia Lewis, head of the London-based Verification Technology Information Centre (VERTIC), who adds, however, that "we're still trying to read between the lines".

Gareth Evans, the foreign minister of
Australia - which has pressed for a zeroyield test-ban treaty - said France had taken "an important step forward", adding that if the decision is confirmed in the treaty it would be a "major breakthrough, exactly the commitment that we have asked from France".

The announcement by Clinton that the

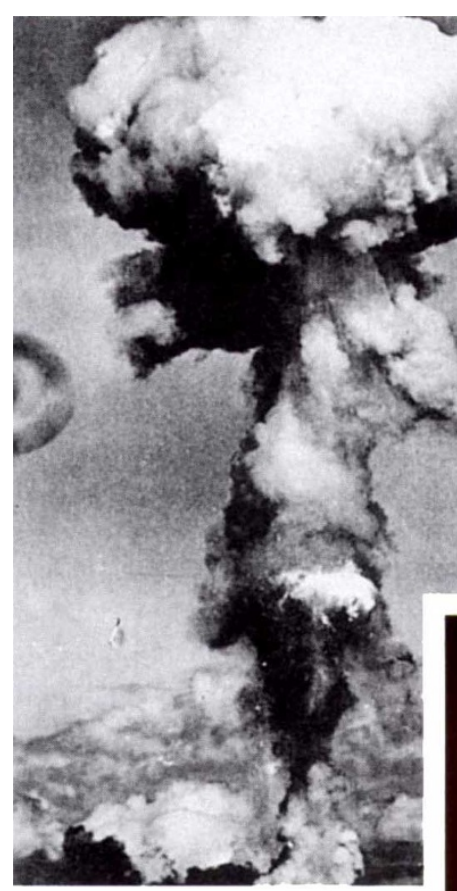

United States will also push for what he described as a "truezero" test ban, ends months of argument within the administraChirac: turns tables on tion about the need for critics of Pacific tests. hydronuclear and other low-

yield nuclear tests, and comes after a panel of leading physicists and weapons designers ruled that the US does not need such tests to assure the safety and reliability of its nuclear weapons stockpile.

The case for hydronuclear tests, yielding less than four pounds of TNT equivalent through nuclear fission, was studied and rejected by a panel convened this summer under the JASON programme, which provides top-level technical advice to the US government. The panel was chaired by Sid Drell, the Stanford physicist, and included the most senior weapons designers at each of the three US weapons laboratories.

An unclassified executive summary of the full, classified report was released by the Department of Energy last week, after parts of it were referred to in a Senate debate on funding for hydronuclear tests. The Senate voted to appropriate $\$ 50$ million for such tests during 1996 - a budget proposal that the Clinton administration will seek to reverse.

The JASON panel found that "a persuasive case has not been made for the utility of hydronuclear tests" in monitoring the reliability of the weapons stockpile. The tests could help to confirm the safety of the weapons in the event of accidental detonation of one of their explosive charges, the panel said, but "the US arsenal has neither a present nor anticipated need for such reconfirmation".

Hydronuclear experiments are used to obtain information on the fission phase of a nuclear explosion. What distinguishes an HNE from a nuclear test is that the chain reaction is stopped before a full yield explosion occurs. HNEs were developed in the US so that they could continue research during the 1958-1961 test ban, when at least one new weapon was developed using HNEs.

The panel also assessed the usefulness of other types of nuclear tests and experiments that have been proposed as alternatives to full-scale weapons testing. It found that 'reduced yield' tests of up to 500 tonnes TNT equivalent yield from fission could help to ensure stockpile reliability.

But such tests would be useful only if they were continued indefinitely, it said, so the US should not propose them unless it intends to downgrade the Comprehensive Test Ban Treaty to a threshold test-ban treaty. Clinton subsequently announced that the US will push for a ban on such low-yield tests, which some in the Pentagon had wanted to conduct.

But the panel said that so-called hydrodynamic experiments - which use chemical explosives to compress uranium and plutonium, and provide data on the sequence of events between the detonation of a warhead up until the start of the nuclear chain - are useful, and should continue. These are not expected to be covered by any test-ban treaty, because they do not involve a nuclear chain reaction.

Clinton said, however, that the US would reserve the right to withdraw from any test ban on the grounds of "supreme national interest", for example if it ever lacked confidence in a needed weapon. This condition was said to be needed to win support from the joint chiefs of staff, and William Perry, the Defense Secretary for his call for a total test-ban.

Declan Butler \& Colin Macilwain 